\title{
CRÉER À LA CROISÉE DES CULTURES : LA CHAIR DU MAÎTRE DE DANY LAFERRIÈRE ET SON ADAPTATION CINÉMATOGRAPHIQUE PAR LAURENT CANTET
}

\author{
Katarzyna WóJCIK \\ Université de Varsovie
}

\begin{abstract}
En): Literature and cinema can be considered as a ground for transnational exchange, both at the level of fiction and artistic creation. The collection of short stories La Chair du maitre (1997) by Dany Laferrière - a Quebec writer of Haitian origin - is an example of this literary creation that passes through national borders and inscribes experiences from another culture into Quebec's literary field. Laferrière's text served as inspiration for French director Laurent Cantet, who put on screen chosen short stories in the film Vers le sud (Heading South, 2005). Cantet's film is not only a filmic transposition of a "transnational" literary work, but also, as a FrancoCanadian co-production, it is itself an artistic practice that crosses the borders between cultures. Through the analysis of Laferrière's text and of the modifications resulting from its film adaptation, the article intends to question the image that the two creations offer of cultural communities - Haitian and North American (and Quebecois) - as well as the way in which they problematize contacts between cultures. Their image is constructed by choices at the level of the plot and the enunciation of the adaptation as well as by the intertextual (and interdiscursive) relationships it maintains with the European film and pictorial imagination.
\end{abstract}

Résumé (Fr): La littérature et le cinéma peuvent être considérés comme terrain d'échanges transnationaux aussi bien au niveau de la fiction que celui de la création artistique. Le recueil de nouvelles La Chair du maître (1997) de Dany Laferrière - écrivain québécois d'origine haïtienne - est un des exemples de cette création littéraire qui traverse les frontières nationales et inscrit des expériences d'une autre culture dans le champ littéraire québécois. Le texte de Laferrière a servi d'inspiration au réalisateur français Laurent Cantet qui a mis sur l'écran des nouvelles choisies pour réaliser le film Vers le sud (2005). En plus d'être une transposition filmique d'une œuvre littéraire « transnationale », le film de Cantet, coproduction franco-canadienne, est lui-même une pratique artistique qui dépasse les frontières entre les cultures. À travers l'analyse de cette œuvre de Laferrière et les modifications qui découlent de son adaptation filmique, l'article se propose d'interroger l'image que les deux créations proposent de deux communautés culturelles haïtienne et nord-américaine (i.e. québécoise) - ainsi que la façon dont elles problématisent les contacts entre les cultures. L'image de ceux-ci est construite par les choix au niveau de l'intrigue et de l'énonciation de l'adaptation ainsi que par les relations intertextuelles (et interdiscursives) qu'elle entretient avec l'imaginaire filmique et pictural européen.

Keywords (En): film adaptation ; Haiti ; Quebec literature ; transnational cinema

Mots-clés (Fr): adaptation cinématographique; Haïti ; littérature québécoise ; cinéma transnational

La littérature et le cinéma peuvent être considérés comme terrain d'échanges transnationaux aussi bien au niveau de la fiction que celui de la création artistique. En raison de son actuel mode de production et de diffusion, le cinéma semble un art «transnational» par défaut. Les coproductions, les premières lors de festivals internationaux et la diffusion rapide auprès d'un public international font que les films s'adressent souvent aux spectateurs de différentes cultures. Le cinéma sort des frontières nationales aussi en ce qui concerne ses sujets et son esthétique. Il s'agit d'une part des récits qui racontent la diversité culturelle, les contacts entre les 
cultures au sein d'une communauté ou entre différentes communautés culturelles ; d'autre part, il y a des relations intertextuelles - thématiques et esthétiques - avec des films des autres cinématographies. C'est pourquoi, au lieu de parler d'un « cinéma national», Andrew HigSON propose le concept de « cinéma transnational ». Celui-ci signifierait une production filmique qui, d'une part, reflète la diversité de la culture nationale et, d'autre part, par ses conditions de production, de financement mais aussi par ses sujets et son esthétique, dépasse les frontières nationales (2000:63).

La littérature a fonctionné dans les limites nationales plus longtemps que le cinéma. Mais elle se voit, elle aussi, de plus en plus souvent conceptualisée avec le préfixe «trans- » qui permet de rendre compte de la diversité des expériences traduites dans les œuvres littéraires. Selon Susan STRYKER, Paisley CURRAH et Lisa Jean MOORE, « les lignes impliquées par le concept même de 'trans' sont des cibles mobiles, composées simultanément de multiples déterminants » $(2008: 13)^{1}$. Dans le contexte québécois, le « transnational » est associé à la littérature migrante. Ainsi, Régine ROBIN parle des " écritures transculturelles ou transnationales » en visant des « écritures de l'entre-deux » (2008:210) que d'autres appellent, suite à Robert Berrouët-Oriol ${ }^{2}$ et à Pierre Nepveu ${ }^{3}$, des « écritures migrantes ».

Le recueil de nouvelles La Chair du maître (1997) de Dany Laferrière constitue un des exemples de cette création littéraire qui traverse les frontières nationales et inscrit des expériences d'une autre culture dans le champ littéraire québécois. Les contacts et les échanges entre les cultures se trouvent au cœur de l'écriture de Laferrière, associée au corpus de la littérature migrante du Québec. En tant qu'écrivain haïtien ayant émigré au Québec, vivant à Miami et à Paris, familier avec la culture haïtienne, québécoise, états-unienne et française, Dany Laferrière aborde dans plusieurs de ses textes les questions des relations transnationales. La Chair $d u$ maître a servi d'inspiration au réalisateur français Laurent Cantet qui a porté à l'écran des nouvelles choisies pour réaliser le film Vers le sud (2005). En plus d'être une transposition filmique d'une œuvre littéraire qui peut être considérée comme transnationale, le film de Cantet, coproduction franco-canadienne, est lui-même une pratique artistique qui dépasse les frontières entre les cultures.

À travers l'analyse de l'œuvre de Laferrière et des modifications qui découlent de son adaptation filmique, nous nous proposons d'interroger l'image que les deux créations proposent de deux communautés culturelles - haitienne et nordaméricaine (états-unienne et québécoise) - ainsi que la façon dont elles problématisent les contacts entre les cultures. L'analyse prendra en compte les sujets abordés au niveau thématique, les relations entre les personnages, les procédés narratifs ainsi que les relations intertextuelles.

\footnotetext{
${ }^{1}$ « $[\ldots]$ the lines implied by the very concept of "trans-" are moving targets, simultaneously composed of multiple determinants » (2008: 13) (nous traduisons dans le corps du texte).

2 BerrouËT-Oriol Robert, Fournier Robert (1992), «L'Emergence des écritures migrantes et métisses au Québec », Québec Studies, vol. 14, p. 9-35.

3 NePVeu, Pierre (1988), L'Écologie du réel. Mort et naissance de la littérature québécoise contemporaine, Montréal, Boréal.
} 


\section{La Chair du maître (1997) de Dany Laferrière}

Le recueil La Chair du maître est composé de 24 nouvelles qui constituent une sorte de tableaux de la vie en Haïti. Les nouvelles partagent le même cadre spatiotemporel - Haïti de la fin des années 1970, pendant la dictature de Baby Doc, mais elles sont narrées de points de vue différents. Il s'agit d'une part de la différence de focalisation (la narration à la $1^{\mathrm{e}}$ ou à la $3^{\mathrm{e}}$ personne, focalisation externe ou interne, focalisation multiple). D'autre part, c'est le personnage focalisateur qui change : les récits sont racontés par exemple par un jeune garçon haïtien, par une femme du consul américain en Haïti, par des touristes nord-américaines. Il y a donc des perspectives féminines et masculines, haïtiennes et autres - états-uniennes et québécoises. Se croisent ainsi les regards de différentes nationalités, ce qui donne au système d'énonciation du recueil un caractère transnational ${ }^{4}$.

Les nouvelles racontent diverses péripéties et expériences de la vie à Port-auPrince où les différences de classe s'ajoutent à celles de race et forment un cadre où comptent le pouvoir du plus fort, l'argent et le sexe. À côté des nouvelles focalisées sur la vie des Haïtiens, il y a des textes qui parlent de l'expérience des Blancs venus en Haïti et côtoyant au quotidien la société haïtienne ou enfin, de celle des touristes qui n'y arrivent que pour une période courte mais cruciale dans leur vie. Pour une analyse plus détaillée, nous allons privilégier les nouvelles choisies pour l'adaptation filmique, à savoir «Vers le sud », «Les garçons magiques » et « La maîtresse du colonel ».

La nouvelle «Vers le sud» est narrée à la première personne par trois personnages féminins - Brenda, Ellen et Sue, et un personnage masculin - Albert. Les narrateurs interviennent à tour de rôle et parlent à un enquêteur silencieux. Il s'agit d'une enquête menée après la mort de Legba, un jeune haïtien qui porte le nom d'un dieu vodou. Issu du milieu défavorisé et mêlé aux affaires de la drogue, Legba est effectivement comme un dieu : dieu de la sexualité et du désir qui exerce une fascination sur les autres personnages.

Les trois narratrices sont des femmes mûres originaires des sociétés nordaméricaines qui arrivent en Haïti pour passer leurs vacances dans un hôtel au bord de la mer. Elles diffèrent par leur appartenance sociale, leur religion, leur profession et leur âge, mais partagent une perspective et une expérience commune, celle de ne pas se retrouver dans la société de leur origine. Brenda, méthodiste d'origine étatsunienne, se sent incomprise par son entourage, en particulier par son mari qui l'a accompagnée à Port-au-Prince il y a deux ans. C'est pendant ce séjour, en rencontrant Legba, qu'elle a enfin découvert le désir et a pu se sentir tout simplement une femme, et non pas une épouse ou une croyante dont la sexualité est réprimée :

« J'ai souffert dans mon corps, dans ma tête, dans mon ventre, dans mon sang, toutes les douleurs imaginables pendant ces deux dernières années. Chaque jour. Chaque nuit. Chaque heure. Pouvez-vous comprendre ça ? Je ne sais pas si on peut comprendre ça quand on ne s'appelle pas Brenda Lee, qu'on ne vient pas d'une petite ville au nord de Savannah, et qu'on ne vit pas

${ }^{4}$ Il est intéressant de remarquer que les voix masculines « occidentales » sont quasiment absentes. Les Américains ou les Européens apparaissent comme personnages ou sont évoqués dans les souvenirs des narratrices, mais ne s'expriment pas comme narrateurs. 
depuis vingt-cinq ans avec un homme qui s'appelle William et qui vous a touchée en tout huit fois » (« Vers le sud », LAFERRIÈRE, $1997: 193)$.

Dans son monologue, elle évoque le moment de cette découverte quand, encouragée par son mari, elle a fait l'amour avec le jeune homme. Cette fois, elle revient en Haïti sans être accompagnée par son époux et retrouve Legba avec qui elle espère avoir une relation amoureuse exclusive. C'est pourquoi elle est jalouse d'Ellen.

Ellen, professeure de littérature de Boston, se sent invisible en tant que femme qui a dépassé la cinquantaine. C'est sur la plage d'Haïti qu'elle peut de nouveau se sentir appréciée comme femme. Certes, elle gagne l'attention des jeunes hommes moyennant l'argent, mais sa relation envers eux n'est pas privée d'amitié et d'attention. Contrairement aux relations homme-femme telles qu'elle les vit chez elle, cette situation a l'avantage d'être, si non socialement acceptée, du moins tolérée : Ellen est la maîtresse de Legba à qui elle offre des cadeaux et de l'argent. Elle est dégoûtée par la société nord-américaine et son hypocrisie en ce qui concerne les rapports entre les sexes, par les filles qui ne veulent que se trouver un mari et les hommes qui pensent seulement à se reproduire et à consommer :

« J'ai fait mes études dans une école privée, et depuis vingt-cinq ans, j'enseigne à Vassar. J'enseigne à de petites mijaurées comment fermer leurs cuisses pour attraper un mari. Si vous croyez que ça a changé, vous vous êtes mis un doigt long comme ça dans l'œil. (Elle fait le geste.) En réalité, mon cours porte sur la littérature contemporaine, mais tout ce qu'elles veulent savoir c'est comment s'arranger pour gagner leur vie avec ce que le bon Dieu leur a donné. Une petite bouche gourmande, deux petits seins qu'elles n'arrêtent pas de regarder pousser, des cheveux blonds et un joli petit cul. Ça fait un paquet dévorable. Et elles n'ont pas tort. Les garçons sont pires. Des ploucs qui ne méritent pas mieux. Je déteste ce pays, même si c'est le mien. Vous ne pouvez pas savoir combien je hais toutes ces petites salopes et tous ces petits cons. Ils ne pensent qu'à se chevaucher pour produire leur marmaille, s'acheter le plus de trucs possible dans leurs supermarchés pour, finalement, échouer comme des cachalots pleins de merde sur une plage de la Caraïbe » (« Vers le sud », LAFERRIÈRE, 1997 : 193-194).

Pour Sue, le sentiment d'incompréhension, voire de rejet, vient de sa corpulence. Elle avoue détester « les hommes de [s]a race » : «Ils ne m'ont jamais regardée. Pour les intéresser, il ne faut pas peser plus de cent vingt livres. Et moi, je pèse le double » (LAFERRIÈRE, 1997 : 194). En Haïti, elle n'est pas jugée selon les codes de beauté nord-américains. Elle s'y sent libre et appréciée. Elle est la seule des trois narratrices à ne pas être amoureuse de Legba, mais de Néptune, un autre jeune Haïtien de la plage. Cela lui donne un rôle de confidente de Brenda.

À part ces trois femmes, dans la narration n'intervient qu'un seul personnage masculin, un Haïtien, Albert. Gérant de l'hôtel et chef du restaurant, il juge sévèrement le comportement de ces femmes-touristes ainsi que celui des garçonsescortes. Originaire d'une famille hostile envers les Blancs, il garde ses distances et respecte le règlement : il s'oppose ainsi à ce que Legba dîne avec Brenda et Sue dans le restaurant de l'hôtel. En même temps, il cède lui aussi devant le charme du garçon.

Dans la nouvelle «Les garçons magiques », il s'agit de la narration à la troisième personne. Le personnage principal, c'est Mauléon, un Haïtien, propriétaire 
d'un nouvel hôtel. Il vient de l'ouvrir sur la terre héritée de son père et cherche un moyen d'attirer des clients pour gagner plus d'argent et ne pas devoir vendre son hôtel. Il découvre alors les "garçons magiques »- des jeunes Haïtiens issus de classes populaires qui passent leur temps avec des touristes étrangères :

«Mauléon les regarde un moment entrer dans l'eau. La femme, très élégante. Le jeune homme, ni trop beau ni trop musclé. Le couple, détendu. Ce qui impressionne Mauléon, c'est qu'ils ne cherchent pas tout de suite une chambre. Ils vont vers la mer. La mer qui n'a pas d'âge. Et face à l'éternité turquoise, soixante ans ne sont pas bien loin de dix-sept ans. Les jeux dans l'eau remontent à l'enfance. L'enfance du monde » («Les garçons magiques », LAFERRIÈrE, $1997: 212)$.

Lorsqu'il interroge le barman d'un autre hôtel à propos du couple, celui-ci explique que les touristes nord-américaines sont attirées par les garçons :

«Mauléon les regarde un moment (ces jeunes corps luisants, ces fous rires, ces jeux enfantins). Les fils du dieu Soleil. Mauléon a subitement l'impression que sa tête va éclater. Il prend tout de suite congé du barman. 'C'est exactement ce qu'il me faut', se dit-il en chemin. Et au lieu de repousser ces garçons magiques, il va les accueillir, les tolérer, les recruter même. Une vraie mine d'or ! » (« Les garçons magiques », LAFERRIÈRE, $1997: 213$ ).

La description du couple composé d'un jeune Haïtien d'origine populaire et d'une Québécoise venue se réchauffer dans le soleil du Sud échappe aux jugements moraux du barman et adopte la perspective de Mauléon. Le narrateur met en valeur la beauté de la rencontre entre l'homme et la femme de l'âge différent, la sincérité des émotions, une certaine insouciance qui ignore les préjugés sociaux.

La nouvelle «La maîtresse du colonel » revient à la narration à la première personne. Le personnage narrateur est un jeune Haïtien, bon élève qui passe les examens. Il est sollicité par une fille de son âge, maîtresse du colonel Beauvais. Elle veut qu'il devienne son ami. Cette situation sert de cadre pour décrire le monde des classes dirigeantes, le milieu des résistants, les jeux politiques et le sentiment d'insécurité indissociable de la vie dans le pays de la dictature. Le narrateur évoque par exemple la peur liée à son nouveau rôle :

« Je n'ai pas fermé l'œil de la nuit, me demandant dans quelle galère je me suis embarqué. De temps en temps, je la vois dans la pénombre : de grands yeux affamés quémandant une affection désintéressée ( "Tu es mon premier ami. Je suis vierge de ce côté. ») Comment peut-on être l'ami de la maitresse d'un colonel. Et pas n'importe lequel : le colonel Beauvais du Corps des Léopards » (« La maîtresse du colonel », LAFERRIÈRE, 1997 : 161-162).

La dimension transnationale est visible aussi au niveau thématique. En fait, les nouvelles racontent les expériences qui viennent du contact avec une autre culture. Il s'agit souvent d'un choc qui permet au personnage de découvrir une autre manière de vivre et de percevoir le monde, voire de se révéler à lui/elle-même. Dans les récits des femmes nord-américaines, c'est la fascination par l'homme haitien en tant que l'Autre qui est mise en avant. Certes, on peut voir dans leur attitude une recherche facile de l'exotisme. Mais, en même temps, l'Autre représente un autre système de valeurs dans lequel la beauté et l'âge comptent différemment. Ainsi, les personnages féminins semblent découvrir ou redécouvrir en Haïti un pays qui leur est familier, 
comme si le système patriarcal de l'Occident leur était aussi étranger qu'il est aux hommes originaires des cultures non occidentales.

Il faut remarquer pourtant que ces découvertes concernent le plus souvent les personnages d'origine nord-américaine. Les personnages haïtiens ne semblent pas évoluer intérieurement, quant à eux, sous l'influence de ces contacts. Cela ne veut pas dire qu'ils sont imperméables aux autres cultures. Dans la nouvelle « Vers le sud », Albert parle de l'influence néfaste de la culture américaine sur Haïti :

\footnotetext{
« Je suis né à Cap-Haitien, dans le nord d'Haïti. Mon grand-père aussi. Je ne sais pas si vous savez ce que ça veut dire. Toute ma famille a combattu les Américains durant l'occupation de 1915. Je viens d'une famille de nationalistes. Mon père est mort sans avoir jamais serré la main d'un Blanc. Le Blanc était pour lui moins qu'un singe. Il disait toujours : « quand je vois un Blanc, j'essaie toujours de le contourner pour voir s'il n'a pas une queue. » Mon grand-père, lui, ne prenait pas cette peine. Pour lui, le Blanc était un animal, un point c'est tout. Il disait : « Le Blanc », mais il pensait surtout à l'Américain. Celui qui a osé fouler le sol d'Haïti. [...] Si mon grand-père savait que son petit-fils sert aujourd'hui les Américains, il en crèverait de honte, cette fois-ci. Ces nouveaux occupants ne sont pas armés. Ils amènent dans leurs bagages un fléau beaucoup plus dévastateur que les canons : la drogue. Et la reine du crime se fait accompagner partout où elle va de ses deux suivantes : l'argent facile et le sexe. Il n'y a rien ici, monsieur, qui ne soit touché par l'un ou l'autre de ces trois fléaux. Autrefois, il y avait une morale. Aujourd'hui, je regarde autour de moi et je vois que tout s'écroule. Je regarde nos clientes, des dames respectables que leur mari aurait accompagnées, il y a une vingtaine d'années, quand j'ai commencé ici. Et que vois-je ? Des femmes perdues, des bêtes assoiffées de sexe. Et qui en est la cause ? Lui, le maître du désir. Il a dix-sept ans, des yeux de braise, un profil pur. Legba : le prince des ténèbres. » (« Vers le sud », LAFERRIÈRE, 1997 : 199-200).
}

Les relations entre les cultures sont donc des relations de pouvoir. Il s'agit d'une lutte constante pour dominer l'autre culture. Et si la culture «blanche », américaine, domine par l'argent, la culture «noire» le fait par le sexe. En fait, plusieurs nouvelles du recueil mettent en scène la domination exercée par les personnages haïtiens sur ceux des autres origines au niveau de relations sexuelles. Les hommes occidentaux sont bien sûr fascinés par les femmes d'Haïti. Mais ce sont surtout les femmes nord-américaines qui tombent sous le joug des hommes, voire des garçons haïtiens. Ce qui compte, c'est évidemment l'argent. Pourtant, ce côté lucratif est souvent marginalisé au profit des relations de classe et de race. Or, il s'agit souvent de la volonté de dominer une femme qui, par son origine, se croit supérieure.

Ainsi, on voit dans La Chair du maître une dimension critique, cachée sous l'humour et l'ironie. Haïti y apparait comme un pays pauvre et hiérarchisé, pays de grands clivages sociaux où le sexe est un gagne-pain facile et les rapports humains sont conditionnés par la recherche de domination. La culture nord-américaine est présentée comme « froide », trop intellectuelle, détachée du corps et de tout ce qui est corporel. En même temps, l'écrivain met en valeur l'authenticité de certaines relations (mère-fils, amour entre les jeunes) et la liberté du désir qui constitue une partie « normale » de la vie des Haïtiens, contrairement à celle des Occidentaux.

Le motif de la domination et de la revanche du dominé sur le dominateur se trouve au cœur du recueil. Il est significatif à ce propos que celui-ci prend le titre de la dernière nouvelle qui semble particulièrement révélatrice de la vision du monde de l'auteur. Le narrateur de la nouvelle « La chair du maître » rend visite à une vielle dame qui habite un quartier riche de Port-au-Prince et l'interroge à propos d'un 
tableau qui décore la maison. La dame lui raconte alors l'histoire de ses ancêtres : un jeune esclave haïtien et une jeune femme blanche, fille de son maître. C'est elle qui s'était éprise du garçon, l'a forcé à faire l'amour, puis l'a sauvé de la mort des mains de son père. Les amants se sont retrouvés après la guerre d'Indépendance : l'ancien esclave devenu général de l'armée avait exigé que l'on épargne la famille de sa bien-aimée. La nouvelle non seulement met en valeur le désir de la femme blanche pour l'homme noir et le rôle du sexe dans les rapports sociaux, mais aussi propose une réflexion sur les relations (post)coloniales. L'expression « chair du maître " se réfère à la jeune fille. Il s'agit d'une attitude revancharde, d'une vengeance qui passe par le corps de la femme. Celle-ci est considérée comme la propriété du « maître », colonisateur blanc masculin. En ce sens, la revanche et la haine qui y est associée ne concernent que l'homme blanc. La femme, quant à elle, se trouve dans une situation de subordination, voire dans une position objectale qui s'apparente à celle de l'homme noir en tant qu'esclave.

\section{Vers le sud (2006) Laurent Cantet}

L'adaptation cinématographique des nouvelles proposée par Laurent Cantet tient compte de ces éléments narratifs et thématiques du texte littéraire qui lui donnent un caractère transnational, tout en effectuant des modifications. On pourrait s'interroger comment cette narration caractérisée par plusieurs perspectives et subjectivités qui raconte le contact des cultures haïtienne et nord-américaine du point de vue d'un écrivain québécois d'origine haïtien est portée à l'écran par un réalisateur français. Laurent Cantet ne partage pas la biographie et la situation « transnationale » de Laferrière. Toujours est-il qu'il se lance dans une expérience artistique qui traverse les frontières entre les nations : porter à l'écran, en tant que réalisateur français, un texte d'une autre aire culturelle (haïtienne et québécoise) qui mobilise plusieurs références.

Le film peut être considéré comme une sorte d'expérience transnationale d'abord en ce qui concerne la production et cela non seulement à cause du texte littéraire de départ. En effet, cette coproduction franco-canadienne rassemble les artistes de différentes origines. Le scénario a été écrit par Laurent Cantet et Robin Campillo, scénariste français d'origine marocaine. Dans le film, on voit des actrices de diverses nationalités - Charlotte Rampling (anglaise, dans le rôle d'Ellen), Karen Young (américaine, qui interprète Brenda), Louise Portal (canadienne, dans le rôle de Sue), ainsi que des acteurs non professionnels haïtiens qui interprètent les personnages masculins.

La pluralité des origines des artistes engagés dans le projet signifie aussi celle des imaginaires et des références culturelles. Certes, ce sont les visions du réalisateur et du scénaristes qui se manifestent le plus facilement dans le film. Mais elles dépassent une dimension strictement subjective et traduisent des idées et des images qui appartiennent au discours social, l'adaptation pouvant être considérée comme une pratique artistique qui fait dialoguer deux imaginaires - individuel et collectif. Selon Jeanne-Marie ClERC et Monique CARCAUD-MACAIRE, dans l'adaptation cinématographique : 
«Le texte original se donne à lire à travers une réécriture qui présuppose une lecture dans laquelle s'inscrit le mode d'appropriation spécifique d'un individu, lui-même inscrit le plus souvent dans un autre temps et un autre espace. À travers cette lecture, c'est aussi tout une société qui se dit par l'intermédiaire de ce qu'elle reconnaît dans le texte initial, mais aussi de ce qu'elle n'en retient pas » $(2000: 11)$.

Tenant en compte cette dimension de l'adaptation - à la fois individuelle et collective - nous nous proposons d'interroger d'abord le choix des nouvelles et les transformations qu'elles subissent dans l'adaptation. En fait, Cantet non seulement ne prend que certains textes, mais il transforme les nouvelles choisies, raccourcit ou omet certains fragments, en ajoute d'autres. Comme on l'a déjà noté, le réalisateur a opté pour trois nouvelles du recueil de Laferrière : "Vers le sud », « Les garçons magiques » et «La maîtresse du colonel». L'information se trouve dans les génériques du film. Pourtant, les titres des nouvelles n'y sont pas indiqués et le discours critique sur le film n'est pas unanime de quels textes il s'agit ${ }^{5}$. Il faut remarquer d'ailleurs que le film s'inspire aussi des autres fragments du recueil ${ }^{6}$.

On peut constater que le réalisateur a choisi les nouvelles les moins liées au contexte socio-politique des années 1970, sauf dans le cas de «La maîtresse du colonel ». Mais même de cette nouvelle, Cantet n'emprunte qu'un motif relativement peu politisé - la conversation du jeune homme (dans le film, il ne s'agit pas d'un jeune élève, mais de Legba) avec la maîtresse du colonel dans la voiture conduite par un chauffeur d'un air menaçant, Frank. Cela servira dans le film à expliquer le meurtre de Legba, devenu une cible pour les gens du colonel ${ }^{7}$. Par contre, le réalisateur omet les parties sur le mouvement des résistants ou les descriptions des classes militaires de la dictature. Il garde pourtant une certaine ambiance de tension du Haïti de la fin des années 1970. Ainsi, la ville Port-au-Prince qui apparaît en toile de fond de l'action est une ville de pauvreté et de grands contrastes sociaux. Le réalisateur traduit le sentiment d'insécurité dans certaines scènes ajoutées dans le scénario, par exemple dans celle où un jeune vendeur de sodas est agressé dans la rue par deux tontons macoutes.

En choisissant les textes « Vers le sud » et « Les garçons magiques », Cantet se focalise sur un phénomène particulier, à savoir le tourisme sexuel. L'adaptation développe l'intrigue de la nouvelle « Vers le sud» et les descriptions de la nouvelle « Les garçons magiques ». Les femmes nord-américaines viennent chercher en Haïti une sorte de paradis pour y passer quelques semaines ou mois de vacances et trouvent des amants parmi des jeunes Haïtiens. Plusieurs scènes présentent des

\footnotetext{
${ }^{5}$ Ainsi, selon la critique journalistique, il s'agit soit de « La Chair du maître », « La maîtresse du colonel » et «L'après-midi d'un faune » (MARTEL, 2006), soit des nouvelles de Vers le sud (recueil publié après la sortie du film) : «La Chair du maître », "Legba », « 3 femmes » (RUER, 2006). Par contre, dans son analyse comparative du film et de l'original littéraire, Mylène F. DorCE constate que ce sont « La Chair du maître », « La maîtresse du colonel » et « Les garçons magiques » (2016:98).

${ }^{6}$ Par exemple la poursuite de Legba par un chauffeur armé ainsi que la relation du héros avec sa mère viennent de la nouvelle L'après-midi d'un faune; les relations entre les jeunes hommes haïtiens et les femmes blanches sont décrites dans Bar de la plage. Si le film semble puiser plus ou moins dans tout le recueil, c'est parce que les nouvelles sont liées entre elles par les personnages. Les personnages principaux reviennent comme secondaires dans d'autres nouvelles ou sont mentionnés dans les dialogues de sorte que tous les textes forment un univers.

${ }^{7}$ Dans la nouvelle, Legba est tué parce qu'il a des relations avec le monde de la drogue.
} 
couples formés d'une femme âgée et d'un jeune Haïtien assis sur la plage, marchant le long du bord ou baignant dans la mer. La scène du pique-nique, ajoutée dans le scénario, $\mathrm{s}$ 'inscrit dans cette représentation paradisiaque où le temps passé ensemble semble un moment de bonheur à la fois pour les femmes-touristes et les garçons haïtiens.

Les scènes évoquées provoquent pourtant une sorte de malaise. Or, privé d'images des autres relations émotionnelles et sexuelles décrites dans le texte littéraire (par exemple celle entre une jeune fille blanche et un jeune Haïtien, celle entre une Américaine qui quitte son mari pour vivre avec un paysan haïtien qu'elle n'a pas connu avant ou, enfin, celle entre Legba et Albert), le film réduit les contacts entre les cultures à une exploitation réciproque, sexuelle et économique. Le pouvoir économique donne aux femmes une certaine supériorité. On peut remarquer, suite à Mylène F. DORCÉ, que « [s]i une certaine lecture de Vers le Sud mène à conclure que les protagonistes noirs exploitent les personnages féminins blancs, une autre perspective fait voir que cette exploitation (sexuelle, financière, immorale) provient en fait bel et bien des personnages blancs [...]» (2016: 83). Selon Dorcé, cette deuxième lecture est favorisée par l'ajout des scènes et dialogues où l'on met en évidence le caractère immoral des relations entre les femmes âgées blanches et les garçons haïtiens ${ }^{8}$. Dans le même sens va l'interprétation proposée par Julie SILVEIRA qui associe le regard de la caméra aux femmes touristes : «Dans Vers le Sud, le regard féminin sur le corps de jeunes hommes prévaut, avec la complicité de l'œil de la caméra. Il s'accorde ainsi avec la position conjoncturellement dominante de ces femmes. Celles qui possèdent le regard sont aussi celles qui détiennent le pouvoir économique » $(2013: 65)$.

Malgré leur fascination pour Legba, Ellen et Brenda semblent complètement inconscientes de la vie que le jeune homme mène lorsqu'il n'est pas avec elles. Cantet ajoute certains dialogues et scènes qui mettent en évidence leur incompréhension de la situation en Haïti et leur attitude de touristes. Ainsi, les deux femmes proposent à plusieurs reprises à Legba de lui procurer un passeport. Elles veulent le protéger, mais en même temps s'approprier de lui, le prendre chez elles pour ne plus devoir faire face à l'indifférence des hommes occidentaux. Brenda fait avec Legba une promenade en ville: si cette scène permet de montrer la rue haïtienne, elle suggère aussi que la femme n'est qu'une touriste qui ne comprend pas la langue, est fascinée par l'étrangeté et l'exotisme (par exemple par le parfum du tabac) et reste pétrifiée devant la vie «réelle» lorsque Legba prend fuite, poursuivi par le chauffeur armé de la maîtresse du colonel.

Un autre type de changement effectué dans le travail d'adaptation concerne la narration. On peut s'interroger si le film adopte une si large variété de points de vue que celle des nouvelles, si la perspective choisie correspond à celle du texte littéraire et enfin, quelles sont les conséquences d'éventuelles transformations à ce niveau.

\footnotetext{
${ }^{8}$ Ainsi, Mylène F. DoRCE cite la scène où Brenda danse avec le petit frère de Legba ou le dialogue entre Brenda et Ellen sur les adolescents haïtiens où cette dernière constate : « Tu n'as que l'embarras du choix. Sers-toi !» $(2016: 83)$.
} 
Comme le texte littéraire, l'adaptation adopte plusieurs points de vue narratifs. La version filmique de «Vers le sud» garde la narration polyphonique de la nouvelle : plusieurs personnages narrateurs s'expriment à la première personne. Cet effet est obtenu dans le film par les scènes d'aveux que les trois protagonistes féminins font au spectateur. En même temps, Cantet omet le motif de l'enquête, ou plus précisément le modifie. L'interrogatoire ne sert plus de cadre aux prises de parole des personnages narrateurs, mais devient un simple élément de l'intrigue : l'enquêteur apparaît à la fin du film afin d'expliquer la mort de Legba. Il n'interroge ni Ellen ni Brenda, les considérant comme extérieures aux événements, et se limite à ce commentaire : «Un touriste ne meurt jamais ». Quant à Legba, il n'intervient que dans les dialogues, ce qui prolonge sa représentation littéraire du personnage qui « n'a pas de voix » (DORCÉ, 2016 : 76). La narration d'Albert n'est pas, comme les autres récits à la première personne, présentée sous forme de monologue devant la caméra, mais sous forme de voix off.

Dans les scènes d'aveux, les femmes semblent s'adresser directement au spectateur: Ellen, Brenda et Sue sont filmées dans leur intimité (le cadre de ces scènes sont leurs chambres d'hôtel), elles regardent la caméra. Leurs récits constituent une sorte de monologues intérieurs prononcés à voix haute, par lesquels elles expliquent des faits à un destinataire fictif aussi bien qu'à elles-mêmes. Leurs voix sont aussi présentes dans certaines scènes sous forme de voix off. Cela privilégie l'expression de la subjectivité féminine. Ainsi, Julie SILVEIRO voit dans ce procédé un moyen d'exprimer le désir des femmes vieillissantes : « Les femmes sont les sujets du récit et du désir. [...] Si on les avait présentées à travers un point de vue masculin, on aurait eu droit, sans doute, à un regard les ridiculisant ou moralisateur » $(2013: 64)$. En même temps, cette narration contribue à augmenter l'écart entre la culture nord-américaine, qui a la parole, et haïtienne, qui reste associée au corps. Selon Mylène F. Dorcé, le personnage de Legba incarne cette dichotomie Nord-Sud: "L'action tourne autour de lui, sans qu'il y participe directement, ce qui démontre que le personnage masculin noir qui n'est pas une macoute, fait partie d'un monde dans lequel il est pour ainsi dire impuissant» (2016: 76).

En même temps, une partie des récits à la première personne de la nouvelle «Vers le sud » et ceux des deux autres nouvelles sont transposés en scènes filmiques «objectives ». On pourrait s'interroger alors à qui appartient ce regard: est-ce toujours le point de vue des femmes-touristes? Ou plutôt celui d'un narrateur extradiégétique qui devient un narrateur filmique neutre? Ou enfin, s'agit-il du point de vue d'un personnage narrateur autre que les trois héroïnes? Si le cadre temporel est celui du séjour des trois femmes à l'hôtel, celles-ci sont observées et accompagnées, à leur arrivée et à leur départ, par Albert. Le gérant de l'hôtel vient chercher Brenda à l'aéroport et à la fin du film, il y emmène Ellen. Certes, il n'est pas possible d'attribuer toutes les scènes à la perspective d'Albert. Mais le film semble s'identifier avec son regard critique : il observe les femmes et leurs jeux avec les garçons « magiques » à la plage et au restaurant de l'hôtel.

Si le point de vue narratif du film correspond à celui des nouvelles par la multiplicité des perspectives des personnages issus de différentes cultures, le choix de personnages focalisateurs et la mise en scène de certaines scènes de manière 
« objective» fait que la narration semble souvent « neutralisée ». Elle manque la force et l'ironie du langage des narrateurs cyniques, langage si caractéristique pour les nouvelles de Laferrière.

En revanche, le film met en valeur l'expérience transnationale par les choix au niveau de la langue parlée par les personnages. La langue - le français - est un élément commun aux artistes. C'est cette langue qui sert à Laferrière pour traduire l'expérience de la culture haïtienne dans le champ littéraire québécois. Dans $L a$ Chair du maître, il ne s'agit pas d'ailleurs uniquement de la culture haïtienne. Le français devient un moyen d'expression «universelle»: tous les personnages s'expriment en français quelle que soit leur origine. Le narrateur sert de relais entre les réalités haïtienne, québécoise et états-unienne, il est en quelque sorte le traducteur de ces expériences variées.

Dans le film, la langue française est dominante, mais pas la seule. Dans la bande sonore, elle cohabite avec l'anglais et le créole, et même au sein du français, il est possible de repérer des variétés. En fait, il ne s'agit pas seulement d'un français standard parisien, mais d'une pluralité de langages qui différent d'un personnage à l'autre : le français parlé en Haïti, le français comme langue étrangère parlée par les anglophones, le français du Québec (dans le film, on souligne le fait que Sue est québécoise, ce qui n'est pas précisé dans le texte littéraire). Les personnages utilisent leur langue maternelle (anglais, français, créole) ou changent de langue pour communiquer entre eux. Ainsi, Ellen communique en français avec Legba, mais s'adresse en anglais à Brenda. Legba utilise le créole avec son petit frère, mais avec les femmes touristes, il parle français. Le réalisateur a ajouté quelques scènes de traduction où un personnage sert d'interprète à l'autre. Ce sont surtout les Haïtiens qui traduisent pour les femmes-touristes. Ainsi, Legba joue le rôle de traducteur pour Brenda au marché. Si cette diversité de langues répond à l'exigence de vraisemblance, le choix de garder plusieurs langues et surtout de les traduire par les personnages eux-mêmes fait que le spectateur partage leur expérience transnationale ${ }^{9}$.

En plus, l'adaptation est marquée par les références culturelles du réalisateur. Certaines images entrent dans un dialogue intertextuel avec l'imaginaire filmique européen. Ainsi, on peut voir dans la représentation des personnages des Noirs et des Blancs au bord de la mer une référence au film Cobra Verde (1987) de Werner Herzog. Si les films racontent des relations entre les cultures des deux époques différentes - le film de Herzog abordant le sujet de la traite des esclaves -, la manière de filmer les personnages par le réalisateur allemand semble avoir nourri l'imaginaire de l'artiste français. Le parallélisme des images incite à la réflexion dans quelle mesure ces deux formes de rapports Nord-Sud - l'esclavagisme et le

\footnotetext{
${ }^{9}$ La présence de plusieurs langues est liée à la question de l'identification : le spectateur choisit un personnage auquel il va s'identifier, mais le film encourage certaines identifications. De cette manière, il augmente ou, au contraire, diminue le sentiment d'altérité envers les personnages et les éléments culturels. Le choix de sous-titrer certaines scènes peut par exemple diminuer le sentiment d'altérité. Le spectateur peut comprendre plus ou moins bien chacune des langues ou, au contraire, toutes peuvent lui être étrangères. Il doit se fier aux traducteurs, comme le font les personnages d'origine états-unienne et québécoise auxquelles il va probablement s'identifier plus facilement pour cette raison.
} 
tourisme sexuel - si différentes qu'elles soient, ne participent pas d'une même attitude colonialiste basée sur les relations de domination et de violence ${ }^{10}$.

Les images du film de Cantet puisent non seulement dans l'imaginaire filmique, mais aussi dans l'imaginaire visuel colonial. Judith Michelmann remarque par exemple que la scène où Ellen observe Legba nu dans son lit après une nuit qu'ils ont passée ensemble participe de l'imaginaire de la peinture coloniale :

Automatically, Cantet evokes all the stereotypes from the exoticism debate around 1900 : the prudish, covered North and the hot South, where humans are no more than body and sex. Like during imperial times, it seems as if the whites try to take possession of the 'natural' and 'wild', because in their own culture it's missing. Ellen tries this in her own way, photographing the naked sleeping Legba. Certainly, this can be interpreted as a gesture of love or a homage to his beauty. But again, it can be seen in succession to, for example, the south-sea pictures of Gauguin in the 19 th century and this connection opens once more the historical code of identity and otherness in modern Europe $(2011: 152)^{11}$.

Ces références renforcent la critique du tourisme sexuel occidental perçu comme une autre forme de colonialisme. Elles s'inscrivent dans les transformations du texte littéraire par lesquelles Cantet critique le tourisme sexuel occidental et la recherche de l'exotisme qui empêche une connaissance en profondeur d'une autre culture. Cantet sensibilise aux inégalités (de race, de classe, de sexe) qui sont liées aux contacts entre les cultures. La critique est tournée avant tout vers la culture nordaméricaine qui colonise par l'argent et profite de la pauvreté des Haïtiens pour assouvir ses désirs. En ce sens, le film semble mettre en valeur le regard critique

\footnotetext{
${ }^{10}$ Le film de Cantet se situe aussi dans un réseau intertextuel avec un autre film, qui lui est postérieur. Il s'agit de Paradis : Amour du réalisateur autrichien Ulrich Seidl, réalisé en 2012. L'action de ce film est située au Kenya. Il met en scène les femmes autrichiennes qui cherchent l'amour chez les jeunes Africains en échange d'argent et de cadeaux. Le sujet commun, celui du tourisme sexuel, y est traité de manière encore plus critique, le film mettant à nu les fantasmes sur les pays exotiques et les autres cultures. On peut remarquer les mêmes motifs et une sorte de parallélisme des images (représentation des corps de jeunes hommes vus par les femmes âgées, perspective féminine, représentation des corps des femmes vieillissantes). Julie SILVEIRA propose de considérer le film de Seidl comme une critique de Vers le sud de Cantet et remarque à ce propos que « l'esthétique crue de Seidl permet d'apprécier la force subversive du 'grotesque', un risque que Cantet a choisi d'éviter » (2013: 70-71).

${ }^{11}$ " Automatiquement, Cantet évoque tous les stéréotypes du débat sur l'exotisme des années $1900: 1 e$ Nord prude et couvert face au Sud chaud où les humains ne sont que corps et sexe. Comme à l'époque impériale, il semble que les Blancs tentent de s'emparer du 'naturel' et du 'sauvage', car c'est ce qui manque dans leur propre culture. Ellen le fait à sa manière, photographiant Legba nu endormi. Certes, cela peut être interprété comme un geste d'amour ou un hommage à sa beauté. Mais encore une fois, on peut y voir une suite, par exemple, aux images des mers du sud de Gauguin du XIX ${ }^{\mathrm{e}}$ siècle et cette connexion mobilise une fois de plus le code historique selon lequel sont perçues l'identité et de l'altérité dans l'Europe moderne » (nous traduisons). Michelmann évoque à ce propos encore deux scènes. La première est celle de l'arrivée de Brenda à l'hôtel. L'image de la touriste blanche suivie par une jeune serveuse noire s'inscrit dans les représentations de la maîtresse avec son esclave. La deuxième scène présente Ellen assise sur une chaise longue qui se penche vers Legba et son petit frère, qui, eux, sont assis dans le sable. La position de la protagoniste met en valeur sa domination par rapport aux jeunes Haïtiens (2011 : 151-152).
} 
empreint des préoccupations d'ordre social présentes dans les autres films du réalisateur ${ }^{12}$.

Pourtant, il serait faux de réduire le film à une image du tourisme sexuel. Laurent Cantet a lui-même insisté sur le fait que Vers le sud dépasse une critique de ce type de domination économique du Nord sur le Sud : " On parle beaucoup du tourisme sexuel quand on parle du film, mais je trouve que ce serait réducteur. J'ai le sentiment que le film parle plutôt du tourisme amoureux. Je pense qu'il y a un véritable échange : les femmes ont besoin, le temps des vacances, de renouer avec elles-mêmes, leur pouvoir de séduction, leur désir et leur corps ; les garçons viennent à l'hôtel un peu pour ces mêmes raisons. [...] Je pense qu'il y a un vrai aller-retour du désir entre les deux groupes » (MARTEL, 2006 : 54-55).

La focalisation sur ce parallèle entre les situations et les besoins des femmes du Nord et des jeunes hommes du Sud rejoint l'idée suggérée dans le texte littéraire, notamment dans la nouvelle éponyme du recueil : ces deux groupes souffrent de la domination patriarcale nord-américaine, que ce soit au niveau sexuel et émotionnel (pour les premières) ou économique (pour les Haïtiens de classes populaires). De cette manière, la création à la croisée des cultures et des nations favorise l'interrogation non seulement sur les clivages, mais aussi sur ce que ces cultures ou nations partagent. Le film semble insister sur la dimension aliénante des normes et des valeurs sociales qui, d'une part, marginalisent les femmes vieillissantes et, d'autre part, mêlent l'amour et l'argent. Il ne s'agirait donc pas tant de la représentation d'une simple opposition entre les oppresseurs et les victimes, que d'une réflexion sur les valeurs culturelles occidentales. L'accusation ne vise pas les touristes féminines, mais la société blanche masculine qui impose ses normes à la fois aux femmes nord-américaines et aux hommes haïtiens.

Malgré les modifications, les omissions et les ajouts par rapport aux nouvelles, l'adaptation prolonge la représentation des relations entre les cultures et les interrogations inscrites dans le texte littéraire. Certes, celles-ci ne concernent que certains aspects, le film se limitant aux trois nouvelles. Toujours est-il que la manière de les porter à l'écran reprend certains procédés littéraires, à savoir la diversité de points de vue narratifs, la mise en valeur du destin individuel par la narration à la première personne et par la forme du monologue, une critique implicite qui aboutit au questionnement des stéréotypes. En même temps, certaines différences s'imposent. Moins ironique et humoristique que le texte littéraire, le film mobilise d'autres registres. Le choix des textes semble ici significatif dans la mesure où il s'agit des nouvelles qui mettent en valeur le tragique du sort des personnages haïtiens au détriment des textes où s'exprime le cynisme du narrateur, dont la nouvelle "La chair du maître ». En outre, les nouvelles choisies engagent de manière importante les personnages non haïtiens. De cette manière, le film offre au spectateur (européen ou canadien) non seulement une image d'Haïti, mais aussi et surtout une réflexion sur la société occidentale. En ce sens, l'origine et le parcours des auteurs s'avère non négligeable. La figuration des rapports interculturels dans

12 On peut évoquer à ce propos le film Entre les murs (2008) qui fait preuve de la sensibilité de Cantet sur la complexité de l'identité, la diversité d'éléments qui forment un individu, sur l'appartenance à plusieurs cultures et l'incompréhension des cultures non occidentales par la société occidentale. 
le texte littéraire semble découler de la situation transnationale de Dany Laferrière. Le regard de l'écrivain est à la fois celui de l'intérieur - il a grandi en Haïti, il y est retourné ensuite comme adulte - et de l'extérieur, sa perspective étant sans doute influencée par la connaissance plus profonde de la culture états-unienne et québécoise et des relations humaines caractéristiques pour les sociétés nordaméricaines. Ces cultures ne le fascinent plus comme quelque chose d'inaccessible. Il en devient plutôt un analyste et commentateur d'autant plus éveillé et ironique qu'il y jette un regard critique et, dans une certaine mesure, détaché. Pour Cantet, il s'agit moins de sa propre condition transnationale que du fait d'adapter un texte littéraire d'une autre culture. L'adaptation mobilise des références culturelles propre au réalisateur et les fait dialoguer avec l'œuvre de départ. De cette manière, elle élargit la réflexion entamée dans les nouvelles. Le cinéaste apporte une autre sensibilité qui ne s'appuie pas tant sur l'ironie que sur une attitude explicitement critique envers la société occidentale et sur une sorte de compassion pour les victimes de celle-ci. Le dialogue transnational et médiatique se prolonge enfin par la réécriture de La Chair du maître qu'entreprend Laferrière. Après la sortie du film, l'écrivain publie le recueil remanié sous le titre Vers le Sud (2006). Si l'ouvrage garde la plupart des nouvelles de la version précédente, le changement même du titre (outre les visées de nature publicitaire) traduit une certaine modification de la perspective où est privilégié non pas un regard ironique haïtien de «La Chair du maître », mais celui, occidental, qui regarde « vers le sud ».

\section{BIBLIOGRAPHIE}

BERROUËT-ORIOL Robert, FOURNIER Robert (1992), L'Émergence des écritures migrantes et métisses au Québec, Québec Studies, vol. 14, p. 9-35.

ClerC Jeanne-Marie, CARCAUD-MACAIRE Monique (2004), L'adaptation cinématographique et littéraire, Paris, Klincksieck.

DORCÉ Mylène F. (2016), Dany Laferrière : de l'écrivain intarissable au cinéaste insaisissable, in : Interculturel Francophonies : Dany Laferrière : mythologies de l'écrivain, énergie du roman, l'Alliance Française de Lecce, p. 73-104.

HIGSON Andrew (2000), The limiting imagination of national cinema, in : HJORT Mette, MackenzIE Scott (éd.), Cinema and Nation, Londres - New York, Routledge, p. 62-63.

LAFERRIÈRE Dany (1997), La Chair du Maître, Lanctôt, Montréal.

MARTEL Denise (2006), Vers le sud. Plus que du tourisme sexuel, Le Journal du Québec, 4 février 2006.

MichelmanN Judith (2011), Re-Organizing Cultural Values: Vers Le Sud by Laurent Cantet, Cinéma Journal Special Issue, no 1, http://cinej.pitt.edu, p. 149158.

NEPVEU Pierre (1988), L'Écologie du réel. Mort et naissance de la littérature québécoise contemporaine, Montréal, Boréal.

RoBIN Régine (2008), Poétiques de la ville, déambulations et nouveaux flâneurs, in: DuMONTET Danielle, ZIPFEL Frank (éd.), Écriture migrante/Migrant Writing, Hildesheim-Zürich-New York, Georg Olms Verlag, p. 201-216. 
RUER Juliette (2006), Cinéma tout compris, Ici, 2 février 2006.

SILVEIRA Julie (2013), De l'indignité au désir : femmes mûres et désirantes dans Vers le Sud, in : BoIsClaIR Isabelle, Dussault FrEnETTE Catherine (éd.), Femmes désirantes. Art, littérature, représentations, Remue-ménage, Montréal. STRYKER Susan, CURRAH Paisley, MOORE Lisa Jean (2008), Introduction: Trans-, Trans, or Transgender?, Women's Studies Quarterly, vol. 36, n 3/4,), p. 11-22. 